\title{
Genetic and Biochemical Analysis of the Ability of Saccharomyces cerevisiae to Decarboxylate Cinnamic Acids
}

\author{
By ANDREW R. GOODEY† AND ROY S. TUBB* \\ The Brewing Research Foundation, Lyttel Hall, Nutfield, Redhill, Surrey RH1 4HY, U.K.
}

(Received 3 March 1982)

\begin{abstract}
Decarboxylation of ferulate to 4-vinylguaiacol is associated with the production of a phenolic off-flavour in beer. The ability $\left(\mathrm{Pof}^{+}\right)$of non-brewing strains of Saccharomyces cerevisiae to carry out this reaction has been assigned, by tetrad analysis, to a single nuclear gene. This gene ( $P O F 1)$ is dominant in heterozygous diploids and segregates independently from $M A T \mathrm{a} / M A T \alpha, \operatorname{lys} 2$ and $D E X 1$. Therefore, elimination of the Pof ${ }^{+}$phenotype from strains intended for brewing is feasible by either mutation or genetic segregation. Since ferulate was decarboxylated by cell-free supernatants derived from $\mathrm{Pof}^{+}$strains, but not by similar fractions from Pof $^{-}$strains, $\mathrm{POF}$ encodes production of a cellular decarboxylase. Strains carrying POFI also decarboxylated coumarate and cinnamate in vivo, but with caffeate, 4-hydroxybenzoate, 4-hydroxyphenylacetate, styrylacetate, mandelate or phenylpropionate as substrates, the corresponding decarboxylation products were not detected. $P O F 1$ may confer resistance to inhibitory effects of naturally occurring cinnamates on yeast growth.
\end{abstract}

\section{INTRODUCTION}

Cereal grains are rich in hydroxycinnamic acids (Wall et al., 1961; Steinke \& Paulson, 1964; Slonimski, 1980). In brewing, these compounds (e.g. ferulic and $p$-coumaric acids) are released when malted barley is extracted with hot water, and, if subsequently decarboxylated, can give rise to phenolic off-flavours in beer (Brumsted et al., 1965; Halcrow et al., 1966; Dadic et al., 1971; Maule \& Thomas, 1973; Wackerbauer et al., 1977; Ryder et al., 1978). Micro-organisms able to decarboxylate ferulate to 4-vinylguaiacol include non-brewing strains of Saccharomyces sp. or yeasts of other genera (Halcrow et al., 1966; Wackerbauer et al., 1977; Gramatica et al., 1981), and enterobacteria (Finkle et al., 1962; Lindsay \& Priest, 1975). In contrast, typical brewing strains of yeast have little or no ability to carry out this reaction (Brumsted et al., 1965; Thurston \& Tubb, 1981).

The rare-mating technique (Gunge \& Nakatomi, 1972; Spencer \& Spencer, 1977) is a potential means of constructing novel strains of yeast for brewing. For example, Tubb et al. (1981 a) mated dextrin-fermenting $\left(\mathrm{Dex}^{+}\right)$haploids with a polyploid lager yeast in an attempt to construct strains suitable for the production of low-carbohydrate beers. However, initial hybrids inherited the unwanted ability of the non-brewing parent to produce 4-vinylguaiacol. A genetic analysis of this Pof $^{+}$phenotype (Pof $=$phenolic off-flavour) has been carried out as a preliminary to constructing hybrid brewing strains which are $\mathrm{Dex}^{+}$but $\mathrm{Pof}^{-}$. In addition we have sought the biochemical nature of the difference between Pof ${ }^{+}$and Pof ${ }^{-}$strains, and the substrate specificity of decarboxylation in vivo.

\section{METHODS}

Strains and genetic techniques. The strains of yeast used in this work are described in Table 1. Growth, sporulation and general genetic procedures were as described by Sherman \& Lawrence (1974). The methodology of Mortimer \& Hawthorne (1975) was used in testing for linkage of genes.

† Present address: G. D. Searle \& Co., High Wycombe, Buckinghamshire, U.K. 


\section{Table 1. Strains of Saccharomyces cerevisae used}

\begin{tabular}{|c|c|c|c|}
\hline Strain & Genotype/description & $\mathrm{Pof}^{+} / \mathrm{Pof}^{-}$ & Source/reference \\
\hline NCYC 1324 & $\begin{array}{l}\text { Polyploid lager strain (syn. } \\
\text { Saccharomyces uvarum) }\end{array}$ & - & $\begin{array}{l}\text { National Collection of Yeast } \\
\text { Cultures (NCYC) }\end{array}$ \\
\hline NCYC 361 & $\begin{array}{l}\text { Dextrin-fermenting strain (syn. } \\
\text { Saccharomyces diastaticus) }\end{array}$ & + & NCYC \\
\hline NCYC 177 & Californian wine strain & + & NCYC \\
\hline NCYC 77 & Baking strain & + & NCYC \\
\hline $\mathrm{DCL}^{\prime} \mathrm{M}$ ' & Distillery strain & + & $\begin{array}{l}\text { Distillers Company Ltd; commercially } \\
\text { available }\end{array}$ \\
\hline BRG 520 & Hybrid strain unsuitable for brewing & + & Tubb et al. (1981 a); strain RDH2 \\
\hline BRG 536* & $\alpha D E X I$ & + & Meiotic segregant of NCYC 361 \\
\hline BRG 530 & $\alpha D E X$ & + & Meiotic segregant of NCYC 361 \\
\hline BRG 526 & a lys2 & - & Goodey $(1980)$; strain SA \\
\hline BRG 161D & a lys $2 D E X 1$ & - & $\begin{array}{l}\text { Meiotic segregant from the cross } \\
\text { BRG } 536 \times \text { BRG 526 }\end{array}$ \\
\hline BRG $162 \mathrm{C}$ & a $D E X I$ & + & $\begin{array}{l}\text { Meiotic segregant from the cross } \\
\text { BRG } 536 \times \text { BRG } 526\end{array}$ \\
\hline BRG $194 \mathrm{C}$ & $\alpha$ his3 lys2 DEXI & + & $\begin{array}{l}\text { Meiotic segregant from the cross } \\
\text { LL-20 } \times \text { BRG 161D }\end{array}$ \\
\hline LL-20 & $\alpha$ leu 2 his 3 & + & Storms et al. (1980) \\
\hline
\end{tabular}

* The single $D E X$ gene in BRG 536 and its derivatives is allelic with that from strain J132b (Erratt \& Stewart, 1978 ), and therefore is assigned $D E X 1$.

Scoring of phenotypes. A Pof ${ }^{+}$phenotype was assigned either on the basis of the production of 4-vinylguaiacol from ferulate or that of styrene from cinnamate (see below). The latter method was more convenient for scoring a large number of tetrads because styrene could be detected in culture media with complete reliability by its typical pungent aroma. A Dex ${ }^{+}$phenotype was assigned on the basis of production of amyloglucosidase as described by Searle \& Tubb (1981).

Assay for decarboxylation of ferulate and other substrates in vivo. Cultures $(10 \mathrm{ml})$ of BRG $520\left(\mathrm{Pof}^{+}\right)$and NCYC $1324\left(\mathrm{Pof}^{-}\right)$were grown at $25^{\circ} \mathrm{C}$ in a medium containing $\left(1^{-1}\right): 50 \mathrm{~g}$ glucose, $10 \mathrm{~g}$ yeast extract, $10 \mathrm{~g}$ bactopeptone, $0.1 \mathrm{~g}$ ferulic acid or other potential substrate (see Table 3), and $10 \mathrm{ml}$ ethanol. Substrates were dissolved in ethanol and added to the basal medium prior to inoculation; control cultures with no substrate were also grown. After $4 \mathrm{~d}$, culture supernatants were extracted and analysed by gas-liquid chromatography for the presence of decarboxylation products (Thurston \& Tubb, 1981). Peaks appearing only on chromatograms produced from cultures of the Pof ${ }^{+}$strain grown with a substrate were identified by reference to pure compounds (where available); 4-vinylphenol was identified by mass spectrometry. Where appropriate, concentrations of decarboxylation products were calculated as described previously (Thurston \& Tubb, 1981), using the following calibration factors: 4-vinylguaiacol, 1.7; 4-vinylphenol, 1.7; styrene, $0 \cdot 33$. Factors for 4-vinylguaiacol and styrene were determined by subjecting known concentrations of the pure compounds to extraction and gas chromatography; that for 4-vinylphenol was assumed to be identical to that for 4-vinylguaiacol and, therefore, is only an approximation.

Preparation and assay of sub-cellular fractions. Cultures $(100 \mathrm{ml})$ were grown to stationary phase in glucose/yeast extract/peptone medium (see above). Cells were harvested by centrifugation and resuspended with their own weight of glass beads ( $200 \mathrm{mesh}$ ) in $10 \mathrm{ml}$ chilled phosphate buffer (120 mM, pH 6.5). This suspension was vortexed for $8 \mathrm{~min}$, interspersed with periods of cooling on ice. Large cell debris, unbroken cells and glass beads were pelleted by low-speed centrifugation $(3000 \mathrm{~g} ; 10 \mathrm{~min})$ and the cell-free supernatant decanted. To locate decarboxylase activity, ferulic acid $\left(0 \cdot 1 \mathrm{~g}^{-1}\right.$, final concentration) was added to (i) the cell-free supernatant obtained after disrupting cells, (ii) the cell debris resuspended in phosphate buffer $(10 \mathrm{ml})$ and (iii) the culture supernatant. In all cases, the amount of 4-vinylguaiacol produced after $1 \mathrm{~h}$ at $25^{\circ} \mathrm{C}$ was measured as indicated above. Protein contents of preparations were determined using the biuret procedure (Herbert et al., 1971).

Chemicals. The majority of hydroxycinnamic acids, related compounds and, where available, their decarboxylated derivatives were obtained either from BDH or from Sigma. The exceptions were ferulic acid, 4vinylguaiacol (Oxford Organic Chemicals, Brackley, Northants) and styrylacetate (Aldrich Chemical Co.).

\section{RESULTS}

Genetic analysis

Strain NCYC 361 was chosen as an example of a wild-type which was both Dex ${ }^{+}$and Pof Po. $^{+}$ This strain sporulated readily but only $5 \%$ of spores were viable. Six such meiotic segregants 
Table 2. Decarboxylation of ferulate by cell-free extracts

Stationary phase cells were disrupted and cell-free supernatants prepared and assayed as described in Methods.

\begin{tabular}{lc}
\multicolumn{1}{c}{ Strain } & $\begin{array}{c}\text { Ferulate decarboxylase activity } \\
{\left[\mu \mathrm{g} \text { 4-vinylguaiacol produced (mg protein) }{ }^{-1}\right]}\end{array}$ \\
BRG 536 & $0 \cdot 11$ \\
LL-20 & $0 \cdot 12$ \\
BRG 520 & $0 \cdot 11$ \\
BRG 526 & $0 \cdot 0$ \\
NCYC 1324 & $0 \cdot 0$
\end{tabular}

were examined: four were Dex ${ }^{+}$(containing one or more $D E X$ genes), two were Dex $^{-}$, but all were Pof ${ }^{+}$. Strains BRG 530 and BRG 536 ( $\alpha$ DEX Pof ${ }^{+}$; Table 1) were chosen for further analysis. The genetically-marked Pof $^{+}$and Pof ${ }^{-}$strains (LL-20 and BRG 526, respectively) were selected from a collection of haploid strains. Of 16 strains tested from diverse origins, BRG 526 was the only Pof- strain obtained.

Heterozygous diploids were constructed by mating BRG 526 with either BRG 536 or BRG 530, and by mating LL-20 with BRG 161D. A diploid tested from each mating was Pof ${ }^{+}$, indicating the dominant nature of this characteristic. Tetrads resulting from sporulation of these diploids were dissected and the segregation of markers scored. In all of 13 tetrads from BRG 526/BRG 536, 12 tetrads from BRG 526/BRG 530 and 10 tetrads from BRG 161D/LL20, Pof $^{+}:$Pof $^{-}$segregated in a ratio of $2: 2$. Therefore, in strains BRG 536, BRG 530 and LL-20, the $\mathrm{Pof}^{+}$phenotype is inherited as a single dominant gene, POF. Since POF :pof segregated 4:0 in all of 8 tetrads from a further cross, BRG 162C $\times$ BRG 194C, it follows that BRG 536 and LL-20 possess the same POF gene, namely POFI. No evidence for linkage between POFI and $M A T \mathbf{a} / M A T \alpha$, lys 2 or $D E X 1$ was obtained.

\section{Biochemical difference between Pof ${ }^{+}$and Pof ${ }^{-}$strains}

Sub-cellular fractions were prepared from three $\mathrm{Pof}^{+}$strains and two $\mathrm{Pof}^{-}$strains and assayed for their ability to decarboxylate ferulate. In no case was activity detected in the culture supernatant or in the pellet obtained after low-speed centrifugation of disrupted cells. The production of 4-vinylguaiacol was specific to cell-free supernatants obtained from $\mathrm{Pof}^{+}$strains (Table 2). Therefore, $P O F 1$ is required for the production of a cellular decarboxylase. In other words, the biochemical basis of the Pof ${ }^{-}$phenotype examined here is a lack of decarboxylase activity, and not for example, failure to transport ferulate into the cell.

\section{Substrate specificity of decarboxylation in vivo}

The association of $P O F 1$ with the ability to decarboxylate ferulate to 4-vinylguaiacol is important in the context of off-flavours arising in brewery fermentations. However, the biological significance of $P O F 1$ may be associated with other decarboxylation reactions. Since activities obtained in crude extracts with ferulate as substrate were rather low (Table 2), examination of a range of substrates was feasible only by assaying for decarboxylation in vivo. In such circumstances, the complete range of substrates for the decarboxylase may well be masked by effects on transport of substrates into, or products out of, the cell. However, in addition to 4vinylguaiacol (from ferulate) the decarboxylation products of cinnamate and coumarate were detected (Table 3). In terms of overall yield of product, substrate specificity was in the following order : ferulate $>$ cinnamate $>$ coumarate. No evidence was obtained for the decarboxylation of caffeate, phenylpropionate, mandelate, 4-hydroxyphenylacetate, styrylacetate or 4-hydroxybenzoate. In addition, neither the production of phenylacetaldehyde from phenylpyruvate, nor 4-hydroxyphenylacetaldehyde from 4-hydroxyphenylpyruvate, was detected. However, Saccharomyces strains can reduce a wide range of carbonyl compounds to the corresponding alcohol (Peppard \& Halsey, 1981). Therefore, if formed, phenylacetaldehyde and 4-hydroxyphenylacetaldehyde are likely to be further metabolized to $\beta$-phenylethanol and tyrosol respectively. Production of these alcohols from the acids added to the culture medium was not measured, 
Table 3. Compounds tested as substrates for decarboxylation in vivo by Saccharomyces cerevisiae BRG 520

\section{Substrate*}

Ferulate

(4-hydroxy-3-methoxycinnamate)

Coumarate

(4-hydroxycinnamate)

Caffeate

(3,4-dihydroxycinnamate)

Cinnamate

4-Hydroxyphenylpyruvate

Phenylpyruvate

Mandelate

( $\alpha$-hydroxyphenylacetate)

Phenylpropionate (hydrocinnamate)

4-Hydroxyphenylacetate

4-Hydroxybenzoate

Styrylacetate

(4-phenylbut-3-enoate)

ND, Not detected.

NM, Not measured because pure compound was unavailable.

* All substrates were added to give a final concentration of $0.1 \mathrm{~g} \mathrm{l}^{-1}$.

$\dagger \mathrm{Rf}$, Retention factor relative to eugenol (internal standard).

$\ddagger$ Based on an absence of any detectable difference in the chromatograms obtained from cultures grown with and those grown without substrate.

since $\beta$-phenylethanol and tyrosol are formed by decarboxylation of aromatic amino acids in Pof- strains ( ̈̈yräpää, 1965; Szlavko, 1973; Thurston \& Tubb, 1981).

\section{DISCUSSION}

The evidence presented demonstrates that a single dominant gene, POF1, enables Saccharomyces cerevisiae to decarboxylate ferulate to 4-vinylguaiacol, a compound responsible for a phenolic off-flavour in beer. Therefore, elimination of the $\mathrm{Pof}^{+}$phenotype from breeding programmes with brewer's yeast is highly feasible either by mutation or by genetic segregation. Using the latter approach, we have described elsewhere (Tubb et al., 1981 b) the construction of dextrin-fermenting brewing strains which produce palatable beer.

Of wider significance to brewing is the fact that the Pof $^{+}$character can be eliminated with ease from the well-characterized, genetically-marked haploids used in fundamental studies on yeast genetics. This should now encourage use of this considerable genetic reserve for the development of brewing yeast by hybridization, either in the conventional way (Johnston, 1965; Emeis, 1971; Anderson \& Martin, 1975; Gjermansen \& Sigsgaard, 1981) by rare-mating (Tubb et $a l ., 1981 \mathrm{~b}$ ), or by protoplast fusion (Russell \& Stewart, 1979; Freeman, 1981). Since representative baking, distilling and wine strains have been shown to be Pof $^{+}$(Table 1), breeding yeasts for other applications does not appear to require removal or inactivation of $P O F$ genes.

The cytoplasmic genetic make-up of haploid or polyploid strains of Saccharomyces can be manipulated independently of nuclear genotype. This process is called cytoduction (see Tubb et $a l ., 1981 \mathrm{~b}$ ) and usually involves a cross where one parent is defective in nuclear fusion (i.e. $\mathrm{Kar}^{-}$; Conde \& Fink, 1976). The assignment of $\mathrm{Pof}^{+}$to a single, dominant nuclear gene provides a marker which can be scored to distinguish cytoductant ( $\left.\mathrm{Pof}^{-}\right)$from hybrid ( $\mathrm{Pof}^{+}$) progeny in crosses between kar POF haploids and Pof- brewing strains. Such an assignment also dismisses a previous suggestion that Pof $^{+}$might be inherited cytoplasmically (Tubb et al., 1981a). 
However, there is evidence (Tubb et al., 1981 ) that replacing the mitochondrial genome of a $\mathrm{Pof}^{+}$strain can alter the amount of 4-vinylguaiacol formed from ferulate during fermentation.

The POF1 decarboxylation system described here appears to be specific for certain cinnamic acids. However, unlike the decarboxylase from Klebsiella aerogenes (Finkle et al., 1962), the yeast enzyme acts on cinnamate itself and, therefore, cannot require substrates to have a particular substitution (e.g. $p$-hydroxyl) in the benzene ring. A similar conclusion can be drawn from the results of Gramatica et al. (1981). These authors reported decarboxylation in vivo of ferulate, coumarate, p-methoxycinnamate and 3,4-dimethoxycinnamate. However, using stationary phase cells from only one strain, they did not detect formation of styrene from cinnamate, a reaction predicted to occur from earlier observations by Chen \& Peppler (1956). Caffeic acid is a substrate for the decarboxylase from $K$. aerogenes (Finkle et al. 1962), but in agreement with Gramatica et al. (1981), we were unable to detect decarboxylation of this substituted cinnamate by $S$. cerevisiae in vivo; possibly it is not transported into the yeast cell.

Some naturally-occurring cinnamates have been shown to possess antimicrobial activity. Gupta \& Banerjee (1976) identified ethyl p-methoxycinnamate as the principal antifungal agent from the East Indian plant, Curcuma zedoaria; more recently, Baranowski et al. (1980) found that caffeate, $p$-coumarate and ferulate increased the lag phase or reduced the growth rate of a Champagne strain of $S$. cerevisiae in a complex medium. Therefore, the ability to decarboxylate these compounds may well confer some resistance to their inhibitory effects.

We are indebted to Mr P. A. Thurston for valuable help and discussion, Mr K. R. Oldfield for skilled technical assistance, Dr T. L. Peppard for determining mass spectra, and Professor E. A. Bevan for the use of a microforge. We wish to thank the Director of the Brewing Research Foundation for allowing us to publish this paper.

\section{REFERENCES}

Anderson, E. \& Martin, P. A. (1975). Sporulation and mating of brewing yeasts. Journal of the Institute of Brewing 81, 242-247.

ÄYRÄPÄÄ, T. (1965). The formation of phenethyl alcohol from ${ }^{14} \mathrm{C}$-labelled phenylalanine. Journal of the Institute of Brewing 67, 341-347.

Baranowski, J. D., Davidson, P. M., Nagel, C. W. \& BRANEN, A. L. (1980). Inhibition of Saccharomyces cerevisiae by naturally occurring hydroxycinnamates. Journal of Food Science 45, 592-594.

BRumsted, D. D., LaUterbach, A. F. \& WeSt, D. B. (1965). Phenolic characteristics in brewing III. The role of yeast. In Proceedings of the American Society of Brewing Chemists Annual Meeting, St Louis, pp. 142145. Madison, Wisconsin: American Society of Brewing Chemists.

Chen, S. L. \& Peppler, H. J. (1956). Conversion of cinnamaldehyde to styrene by a yeast mutant. Journal of Biological Chemistry 221, 101-106.

CONDE, J. \& FINK, G. R. (1976). A mutant of Saccharomyces cerevisiae defective for nuclear fusion. Proceedings of the National Academy of Sciences of the United States of America 73, 3651-3655.

Dadić, M., van Gheluwe, J. E. A. \& Valyi, Z. (1971). Phenolic taste in beer. Wallerstein Laboratories Communications 34, no. 113, 5-14.

EMEIS, C-C. (1971). A new hybrid yeast for the fermentation of wort dextrins. In Proceedings of the American Society of Brewing Chemists Annual Meeting, Montreal, pp. 58-62. Glenview, Illinois: American Society of Brewing Chemists.

Erratt, J. A. \& Stewart, G. G. (1978). Genetic and biochemical studies on yeast strains able to utilize dextrins. Journal of the American Society of Brewing Chemists 36, 151-161.
Finkle, B. J., LeWIS, J. C., CORSE, J. W. \& Lundin, R. E. (1962). Enzyme reactions with phenolic compounds: formation of hydroxystyrenes through the decarboxylation of 4-hydroxycinnamic acids by Aerobacter. Journal of Biological Chemistry 237, 2926-2931.

Freeman, R. F. (1981). Construction of brewing yeasts for production of low carbohydrate beers. In Proceedings of the 18th European Brewery Convention Congress, Copenhagen, pp. 497-504. London: IRL Press.

Gjermansen, C. \& Sigsgaard, P. (1981). Construction of a hybrid brewing strain of Saccharomyces carlsbergensis by mating of meiotic segregants. Carlsberg Research Communications 46, 1-11.

GOODEY, A. R. (1980). Interstrain transfer of genetic elements by protoplast fusion in Saccharomyces cerevisiae. Ph.D. thesis, University of London.

Gramatica, P., Ranzi, B. M. \& Manitto, P. (1981). Decarboxylation of cinnamic acids by Saccharomyces cerevisiae. Bioorganic Chemistry 10, 14-21.

GuNGE, N. \& NaKaToMI, Y. (1972). Genetic mechanisms of rare matings of the yeast Saccharomyces cerevisiae heterozygous for mating type. Genetics $\mathbf{7 0}$, 41-58.

Gupta, S. K. \& BANERJEe, A. B. (1976). Isolation of ethyl $p$-methoxycinnamate, the major antifungal principal of Curcuma zedoaria. Lloydia 39, 218-222.

Halcrow, R. M., Glenister, P. R., BRUMSTEAD, D. D. \& LAUTERBACH, A. F. (1966). Phenolic characteristics in brewing: Part IV: Off-flavours from biological sources. In Proceedings of the 9 th Convention of the Institute of Brewing, Australian Section, pp. 273279. Adelaide: Institute of Brewing.

Herbert, D., Philips, P. J. \& Strange, R. E. (1971). 
Chemical analysis of microbial cells. Methods in Microbiology 5B, 209-344.

JoHNSTON, J. R. (1965). Breeding yeasts for brewing II. Production of hybrid strains. Journal of the Institute of Brewing 71, 135-137.

LindSAY, R. F. \& PRIEST, F. G. (1975). Decarboxylation of substituted cinnamic acids by enterobacteria: the influence on beer flavour. Journal of Applied Bacteriology 39, 181-187.

Maule, A. P.\& Thomas, P. D. (1973). Strains of yeast lethal to brewery yeasts. Journal of the Institute of Brewing 79, 137-141.

Mortimer, R. K. \& Hawthorne, D. C. (1975). Genetic mapping in yeast. In Methods in Cell Biology, vol. 11, pp. 221-233. Edited by D. M. Prescott. London: Academic Press.

Peppard, T. L. \& Halsey, S. A. (1981). Malt flavourtransformation of carbonyl compounds by yeast during fermentation. Journal of the Institute of Brewing 87, 386-390.

Russell, I. \& Stewart, G. G. (1979). Spheroplast fusion of brewer's yeast strains. Journal of the Institute of Brewing 85, 95-98.

Ryder, D. S., Murray, J. P. \& Stewart, M. (1978). Phenolic off-flavour problem caused by Saccharomyces wild yeast. Technical Quarterly of the Master Brewers Association of the Americas 15, 79-86.

SEARLE, B. A. \& TubB, R. S. (1981). A rapid method for recognising strains of yeast able to hydrolyse starch or dextrin. FEMS Microbiology Letters 111, 211-212.

Sherman, F. \& LaWrenCE, C. W. (1974). In Handbook of Genetics, pp. 359-446. Edited by R. C. King. London \& New York: Plenum Press.

Slonimski, B. A. (1980). Phenolic acids in the meal of developing and stored barley seeds. Journal of the Science of Food and Agriculture 31, 1007-1010.

SPENCER, J. F. T. \& SPENCER, D. M. (1977). Hybridization of non-sporulating strains of brewer's and distil- ler's yeasts. Journal of the Institute of Brewing 83, 287 289.

Steinke, R. D. \& Paulson, M. C. (1964). The production of steam-volatile phenols during the cooking and alcoholic fermentation of grain. Journal of Agricultural \& Food Chemistry 12, 381-387.

Storms, R. K., MCNeil, J. B., Khandekar, P. S., AN, G., Parker, J. \& Friesen, J. D. (1980). Chimaeric plasmids for cloning deoxyribonucleic acid sequences in Saccharomyces cerevisiae. Journal of Bacteriology 140, 73-82.

Szlavko, C. M. (1973). Tryptophol, tyrosol and phenylethanol - the aromatic higher alcohols in beer. Journal of the Institute of Brewing 79, 283-288.

Thurston, P. A. \& TuBB, R. S. (1981). Screening yeast strains for their ability to produce phenolic offflavours: a simple method for determining phenols in wort and beer. Journal of the Institute of Brewing 87, 177-179.

Tubb, R. S., Brown, A. J. P., Searle, B. A. \& Goodey, A. R. (198la). Development of new techniques for the genetic manipulation of brewing yeasts. In Current Developments in Yeast Research, pp. 75-79. Edited by G. G. Stewart and I. Russell. Oxford \& New York: Pergamon Press.

Tubb, R. S., Searle, B. A., Goodey, A. R. \& Brown, A. J. P. $(1981 b)$. Rare mating and transformation for construction of novel brewing yeasts. In Proceedings of the 18th European Brewery Convention Congress, Copenhagen, pp. 487-496. London: IRL Press.

Wackerbauer, K., Kossa, T. \& Tressl, R. (1977). Formation of phenols by yeasts. In Proceedings of the 16th European Brewery Convention Congress, Amsterdam, pp. 495-505. Zoeterwoude: European Brewery Convention.

Wall, J. S., Swango, L. C., Tessari, D. \& Dimler, R. J. (1961). Organic acids of barley grain. Cereal Chemistry 38, 407-422. 